\title{
Copyright Reform: Imagining More Balanced Copyright Laws
}

Michelle M. Wu

Georgetown University Law Center, mmw84@law.georgetown.edu

This paper can be downloaded free of charge from:

https://scholarship.law.georgetown.edu/facpub/2282

https://ssrn.com/abstract=3624021

Forthcoming chapter Copyright Reform: Imagining More Balanced Copyright Laws, in Michelle M. Wu, Copyright, Libraries, and the Public Interest (Hein).

This open-access article is brought to you by the Georgetown Law Library. Posted with permission of the author. Follow this and additional works at: https://scholarship.law.georgetown.edu/facpub

Part of the Collection Development and Management Commons, Intellectual Property Law Commons, and the Law and Society Commons 
The following chapter is the last chapter in the book Copyright, Libraries, and the Public Interest by Michelle M. Wu (Hein, forthcoming 2020), and this draft version is being posted with the approval of the publisher.

Earlier chapters of this book provide a history of copyright and libraries in the United States, a review of outdated language in the existing copyright code, and a discussion of actions by both copyright owners and the public to rebalance copyright outside of legislation. This chapter simply imagines what copyright could be if we disregard the known political and legal obstacles. It starts with no constraints, which one might argue is both impractical and foolish. Why spend time discussing what could be when treaties, self-interest, and powerful industry lobbies stand in the way?

The answer is simply that environments can be changed. They have been changed throughout history, whether through legislation (e.g., copyright terms), case law (e.g., fair use in relation to technology), or ground roots movements (e.g., the initial movement to recognize authors' rights). And if one hopes to change history, why not start first by exploring possibilities that we might not consider otherwise? Refusing to consider change out of fear of opposition translates to a voluntary surrender of power.

Beginning with restraints also blinds one to possibilities of a much better construct than could be achieved with them. If everything has to fit in a box, people will often discard anything they think won't fit at the outset. Only by removing the box can we imagine the full range of benefits of a given course of action. If the outcome is desired, then efforts can turn to whether or not there is a way to fit the outcome into the box. Or to decide if the benefits are so great that destruction of the box is in society's best interest. A vision should start with where one thinks the world should be, and then reality can help to shape the path.

Because this is the last chapter in the book, to fully understand how the guiding interests were chosen, one would need to read the preceding chapters. 


\section{Michelle M. Wu, Chapter from Copyright, Libraries, and the Public Interest}

\section{Chapter 11 \\ Copyright Reform: \\ Imagining More Balanced Copyright Laws}

It is doubtful that the enactment of further merely partial or temporizing legislation will afford satisfactory remedies for the insufficiencies and inconsistencies of the present laws. The subject should be dealt with as a whole, and the insufficient and antiquated laws now in force be replaced by one consistent, liberal, and adequate statute. ${ }^{466}$

Building on the interests honed in the last chapter, this chapter proposes a new set of building blocks for copyright. Unlike section II, no model language is proposed as the emphasis is on the outcomes, not on the advantages or disadvantages of any specific wording. Where there is support for any principle, wordsmithing can come later.

This book is not the first to take a clean-slate approach. Giblin and Weatherall attempted the same in their book, What if We Could Reimagine Copyright?, ${ }^{467}$ and in some ways, that was a more thorough endeavor, attempting a world-wide view with each chapter focused on a different author's vision on a particular topic within copyright. This book differs in that it focuses only on the United States, its history, and identified interests, disclaiming the necessary expertise to understand all of the motivations for copyright in the many regimes found across the world. It is more unified, though, as all proposals are designed to work with each other in mind.

Even though this approach may seem insular, that is not its intention. Recognition of copyright worldwide, and respect for the rights of authors and the public in all nations, is important and compelling. From a practical perspective, though, how nations implement copyright is already so varied, despite the existence of copyright treaties, that the current system cannot be considered unified or consistent. The framework articulated below could well be proposed worldwide, but in its reasoning, it does not account for each country's priorities nor does it pretend to present a weighting system that could accommodate them all in equal measure.

To start, I will list again the interests that underlay the proposals below: 1) rewarding the creation of works (private interest, full weight); (2) rewards proportional to the contribution to the creative work (private interest, full weight); (3) preventing reputational damage (private interest, discounted weight); (4) wide access to information and preservation of the same (public interest, full weight); (5) protection of limited, unpaid uses where public benefit outweighs injury to the first interest (public interest, full weight); (6) growing the public domain to encourage future creation of works and wider access (public interest, full weight), and (7) creating sufficient incentives for secondary players to assist creators in bringing their works to market (public interest, discounted weight).

Each subsection below will describe a proposed part of the overall framework, which of the interests are served by the subsection, and how they will be served.

\footnotetext{
466 S. ReP. No. 1108, at 2 (1909) (citing ThORVAld SolberG, Copyright In CONGRESS, 1789-1904 (1905)).

467 WHAT IF WE COULD REIMAGINE COPYRIGHT? (Rebecca Giblin \& Kimberlee Weatherall eds., 2017), https://www.jstor.org/stable/j.cttlq1 crjg.
} 


\section{Michelle M. Wu, Chapter from Copyright, Libraries, and the Public Interest}

\section{Exclusive rights}

The exclusive rights that an author would control during a copyright term would be similar to the ones recognized today, though there would be one notable change. The current rights are reproduction, distribution, the creation of derivative works, public performance, and public display. This proposal suggests expanding the "public" qualifier to the first and third of these rights, therefore removing the author's control of any private action undertaken by a user in the normal course of using a copy of a work that she has legitimately acquired.

Of the interests named in the introduction, this altered language aims to protect limited, unpaid uses where public benefit outweighs injury to the private interest of author income and control. No legitimate author interest is served by limiting a user's access to a copy that she has legitimately acquired. The author would have already been paid for his work when the copy was first sold, so any private interest in being paid for this copy is satisfied. The public benefit from the narrowing of rights comes in the form of users being able to use the work in the manner and form most suited to their needs.

How this might be expressed is in a revised listing of rights is: reproduction for non-personal use, public distribution, derivative works exposed to public use, public performance, and public display. Personal use would then be defined as individual use by the owner of a legitimately-acquired copy of a work while she has legal possession and control of that legitimately-acquired copy.

This language would mean that that someone who buys a copy of music could duplicate it for the purpose of her personal use on multiple devices. Or, if she buys an e-book, she can use screen reading software to create an audio file for playback on her way into the office. She would be free to abridge or translate a work (i.e., create a derivative work) for her personal use. But should any of the copies or derivative works that she has made be disseminated beyond herself, she loses the protection written into the definition and would open herself to infringement claims.

\section{Duration}

Legislatures continue to extend copyright with the expressed hope of giving greater economic security to authors and reducing the ability of others to profit from the work without payment, but every enactment has benefitted commercial entities above all others. This section aims to better balance the interests of copyright by recognizing that the interests of all cannot, and need not, be met by a single term. By looking at the legitimate issues of each group --- an author's desire to make a living from their work, the public's hunger for greater access, and the industry's need for sufficient profit to justify investment in creative works - one can see a path forward that will speak to every interest. By splitting the term of protection based on use, the nation could protect both the creator and the public more effectively.

\section{Short Term for Free Uses}




\section{Michelle M. Wu, Chapter from Copyright, Libraries, and the Public Interest}

Independent researchers the world over have proven that long copyright terms help only a very small minority of individuals. ${ }^{468}$ If the purpose of copyright is to encourage the creation of new works, this can effectively be accomplished by providing a short copyright term of 20 years from publication. This term is loosely derived from Pollock's calculations for the optimal copyright term, based on books and recordings, of fifteen years. ${ }^{469}$ Another scholar, Giblin, makes the argument that while terms should be shortened, each type of work should have a different term, and she provides as an example the value of software as having shorter commercial longevity than films. ${ }^{470}$ While true, I have opted to treat most works as the same, using the same shortened term, slightly longer than Pollock's optimal term, for simplicity for the user. This is same reason that drives the marker for the start of the term back to the publication date instead of the author's life. The latter is highly variable and may require significant research, ${ }^{471}$ whereas the publication date should be more easily found.

Within those first 20 years, the author would have all the exclusive rights normally associated with copyright - as described and modified above - with the few exceptions described in later subsections. After those 20 years, a work could be freely used, but only for non-commercial uses.

In practice, what would this mean? It means that 20 years after publication, any entity could legally reproduce an unlimited number of copies of that work or post it online; if that work is a musical, it could be performed in schools without paying license fees; and documentarians could freely use photos, film clips, and artwork from the work, up to and including using the whole work (e.g., running commentary on a film) as desired.

To counter legitimate criticisms by creators that their works are exploited for great economic gain by non-creators once they fall into the public domain, this short-term would only be applicable where the subsequent use carries no commercial weight. For example, if an organization wishes to post a full-text book online without restriction twenty-one years after publication, it may do so. If it chooses to charge for access to that same work, though, it would be seen as a commercial enterprise and would be ineligible to use the work without payment to the author (see the following subsection).

There are, of course, many ways an entity could derive indirect commercial benefits from the free use of creative works. For example, a bookseller could make content available for free but charge for printing and binding if readers wanted a physical format over a digital one, or a movie theater could still charge the cost of a seat if viewers wish to see a movie set in its intended arena. In theory, these entities could mark up the services such that they cost as much as the work would have cost if still protected by copyright. Such markup would not be prohibited, but two effects of the shorter term for free uses should minimize the chances for exploitation.

First, there will very likely be multiple entities that make the work freely available in multiple forms, whether public libraries, organizations like the Internet Archive, or simply individuals who are fans of the work. Second, other organizations are free to offer the same added services at lower costs. In other words, the environment would be one that is highly competitive,

\footnotetext{
${ }^{468}$ Patry, supra note 201 at 59; See also, infra Chapter 9: Copyright Reform - Reviewing Ongoing Proposals, Sections on Reinstating Formalities and Duration

${ }^{469}$ Rufus Pollock, Forever Minus a Day? Some Theory and Empirics of Optimal Copyright 26 (Munich Pers. RePEc Archive, Paper No. 5024, 2007), https://mpra.ub.uni-muenchen.de/5024/1/MPRA_paper_5024.pdf.

${ }^{470}$ Giblin, supra note 372 at 199.

${ }^{471}$ Patry, supra note 201 at 194.
} 


\section{Michelle M. Wu, Chapter from Copyright, Libraries, and the Public Interest}

where unreasonably marked up costs are unlikely to be rewarded by the consumer, even the consumer willing to pay for a different format than is freely available.

Overall, the shorter term determined by use is designed to give the author the strongest opportunities to generate income from their work during the years that the work will be most commercially viable. Admittedly, this short term disadvantages the most popular authors, but copyright is not intended to maximize profits, only to put the author in a position to make a living from their works. As there will continue to other income streams available to the popular author (some examples described in the next section), the loss of some revenue to a minority of creators does not justify the harm to the public resulting in a longer term.

After 20 years, the public interest outweighs the minimal benefit the author would claim by keeping the same level of control, and the work is released to all to use for free. The author, if he desires the same level of control or opportunity for income, will need to create new works or derivative works. And the public domain is enriched, as the shorter term enables wide dissemination of the original work and non-profit derivative uses.

\section{Extended Term for Commercial Use}

This section addresses any use that does not fall into the category of free use, and it proposes a longer term of protection: 100 years after publication. For ease of using shorthand, we will call this use commercial use and define it broadly as any use that charges the user for the content of the work. The categorization of the actor or industry - for-profit, non-profit - is irrelevant to the commerciality of the use itself. Either it charges for content or it does not. In other words, whether a bookstore or a library charges users for a content of a book, neither could do so during the term of protection without paying the author. ${ }^{472}$

The term of protection for commercial use is a bit arbitrary, not based on any study or economic analysis, but rather designed to be lengthy enough to discourage any industry from waiting out the copyright period before exploiting the work (e.g., making a movie from a popular book). The same factors that have narrowed the diversity of creative works - the desire only to invest in products, genres, stories, that are already known to be successful ${ }^{473}$ - will in this instance work in favor of the author.

Hot properties often do not hold their allure for long, and it is in the interests of large corporations to strike when interest is high. A 20-year term of protection may not necessarily dissuade companies from delaying use, especially where a property is a serial one with continued popularity (e.g., Harry Potter), but a corporation's willingness to wait a hundred years is unlikely for the same reason that economists have determined that the present value of a long copyright term will

\footnotetext{
${ }^{472}$ Note that any entity could still provide a kiosk where a user could print out a book and pay for the number of pages copied. That would not be a commercial use of the content, as the charge would be for the paper/ink.

${ }^{473}$ Patry, supra note 201 at 23-27 (providing anecdotal data to illustrate how incentives actually make those who make the most profit off of copyright - such as motion picture industries -- reluctant to risk. They want to invest primarily in works that they know will be successful, so derivative works, instead of culturally diverse works get greenlit.).
} 


\section{Michelle M. Wu, Chapter from Copyright, Libraries, and the Public Interest}

not incentivize creation or investment in creation. ${ }^{474}$ It is the potential for current or short-term revenue that factors most heavily in decision-making.

During this 100-year term, the creator's work would receive the maximum protection from copyright as against commercial uses, and any prospective user would have to negotiate terms in the usual manner, either directly with the creator, or through licensing organizations, managers, or others as designated by the creator. This is where the purpose of the split term becomes evident. As seen in the testimony reproduced in the earlier chapters, authors have long complained that when a work falls into the public domain, the only people who benefit are industry actors. The split term essentially creates an early public domain while still requiring payment for commercial uses. While this will not address the author's concern after the 100-year period passes and the work truly passes into the public domain, it does counter the argument that terms cannot be shortened without disadvantaging the author in favor of industry giants.

There will, of course, be exceptions and instances where even a 100-year term will not prevent an industry from profiting from a work without payment to the creator. Examples today would include the many public-domain adaptations of Little Women, Sherlock Holmes, and Pride and Prejudice. In the end analysis, though, there are relatively few works able to achieve this level of continued success, and ultimately, the desire is not to prevent entertainment industries from eventually benefitting from the public domain, much as the general public does, but simply to weight the scales such that authors are more likely than not to gain much of that financial benefit over the course of their lives.

\section{Compulsory Licensing}

To avoid disuse in the 100-year term while a work is still commercially viable, whether that disuse is through purchasing a work and then suppressing it ${ }^{475}$ or simply discontinuing publication, ${ }^{476}$ reproduction and distribution of those reproductions would be authorized under compulsory licensing where a work becomes unavailable for a year after commercial publication or after delivery of a work for publication. The first standard would be for works published but falling quickly out of the market; in such cases, any other commercial user would have the ability to exploit the work within the 100-year period, but only with some payment to the creator.

The alternative --- one year after delivery of a work for publication --- is intended for instances where the purchaser buys publication rights only to suppress the work. Since suppression flies against every interest in copyright, compulsory licensing appropriately subverts such intent by permitting publication even before any commercial distribution has occurred. In these instances, alternative publishers would not know of the delivery date without assistance.

\footnotetext{
${ }^{474}$ Brief of George A. Akerlof et al. as Amici Curiae in Support of Petitioners at 8-10, Eldred v. Ashcroft, 537 U.S. 186 (2003) (No. 01-618), https://cyber.harvard.edu/openlaw/eldredvashcroft/supct/amici/economists.pdf.

${ }^{475}$ David Voreacos, Chris Dolmetsch, \& Gerry Smith, Tabloid Company's Admission Shows New Peril for Trump's Circle, BLOOMBERG, https://www.bloomberg.com/news/articles/2018-12-12/american-media-in-non-prosecutionagreement-with-prosecutors

${ }^{476}$ See supra note 401.
} 


\section{Michelle M. Wu, Chapter from Copyright, Libraries, and the Public Interest}

In both instances, a free registry could alert potential commercial users to the availability of a work, and the population of the registry would depend on creators. In the first instance, the author could provide a description of the work, link to the publisher, insert the publication date, and certify the date the work was no longer available from the publisher. Most of the information could also be independently verified by the prospective user. In the second instance, the author could provide a description of the work, upload the agreement for publication (with any personal details stricken for privacy reason), and certify the date of delivery of the work. Any user wishing to publish the work would need to notify the rightsholder (as noted in the registry) of such intention 30-days prior to publication. This allows that rightsholder to object to falsified or incorrect data submitted by the author.

Compulsory licensing would preserve income streams for authors whose works fall out of "print" in the normal course of publishing, as other publishers might be willing to market and sell the work where the original publisher no longer has interest. Compulsory licensing prices would be preset, whether by the government or an independent, external organization, and would automatically adjust with inflation.

\section{Hybrid Uses}

The greatest challenge in application of the split term is likely to fall in the area of remixes where the 20 -year term has passed but the 100-year term is ongoing. Remixes would include efforts such as colorization of movies, sampling of songs, the use of movie clips in other movies, and inclusion of photographs or artworks in books.

If the remixer makes the subsequent work available for free, there is no question. The use clearly falls under the 20-year term and can be undertaken without payment to the original creator. But if the remixer charges for the subsequent work, even if the majority of the work is his own (e.g. where only 5-beat sample from one work is used in another), then the 100-year term applies.

I could foresee, though, a hybrid approach, where a remixer charges a lower market rate for the remix, claiming that access to the portions of the original work is free, and that the charge is only for the added content. For example, if the average market price for a song is $\$ 1$, a remixer might charge only 80 cents for a remix, where less than $20 \%$ of his remix is comprised of pre-existing works.

Logically, this approach is sound and acknowledges both the public and author interests of copyright. Due to the moral rights outlined below, the author of the original work would receive credit for her portion of the new work, and ideally, more users listening to her original work due to new exposures through the remix. The new revenue reaching the remixer rewards both the new creation and the creative use of a preexisting work. Since the use is one that the original author did not instigate, she should have no expectation of income from it. The reward rightly goes to the creation of a new work and the exposure of a pre-existing work to new audiences, both principle interests of copyright. And the reduction of reward is proportional to the amount of pre-existing works used, preventing unjust enrichment, which is also an interest this framework seeks to protect.

Practically speaking, though, many cases may not be as straightforward. For instance, how would a production company measure the value of coloration versus the content of the original 


\section{Michelle M. Wu, Chapter from Copyright, Libraries, and the Public Interest}

movie? The original work has value without the added content, but the added content does not have any value without the original. Cases such as these might need to be adjudicated by courts or alternative dispute resolution mechanisms and will likely be expensive endeavors as each side attempts to justify whatever calculations they believe to be fair.

\section{Moral Rights}

Some of the concerns raised by authors in the use of their work are analyzed best through the lens of a natural right. A natural right is one that is described as not attaching through the grant of a government or other institution, but rather naturally attaching to an individual. ${ }^{477}$ In relation to copyright, a natural rights argument would be that a work is an extension of the author and is attached at creation so requires no recognition by a government to exist.

Since a work is the expression of an individual, its creator may feel that they have a personal stake in the use of their work. Where a work reflects on the author, one can sympathize if she feels more keenly its misuse, as such misuse has the potential not only of affecting her immediate revenue stream but also her reputation and future business. At the same time, public interest weighs against allowing an author's personal feelings to dictate all uses of a work, certainly in the long term but also in some cases in the short term. For example, an author's personal feelings should not allow her to restrict access to a book only to those of a certain religion or nationality, though she certainly could choose a publisher more likely to reach a specific target audience.

In the battle over moral rights, the public interest lies mostly in access and preservation, whereas an author's interest falls almost entirely in use, and it is in recognition of this difference that a new framework for moral rights is suggested, one which does not limit access to the work but enables the creator to sanction or censure the use if desired.

This new moral rights protection would run until the author's death, whether the use is commercial or not. The length of this right is calibrated to its purpose. Since an author's reputation is the one that faces potential harm from use of her work, and since an author could only be presumed to support a use when alive, the interest dies upon her passing. While reputations might still be harmed after death (e.g., criticism of the person or work), a work's use no longer holds the power of implied creator approval when the creator no longer exists.

The rights would only attach to the creator, not to subsequent copyright owners; would apply only to human and not corporate creators; and would not apply in cases of works-for-hire. All of these limitations can be explained by the nature of the right. It is personal, so attaches only to the individual person who created the work in question.

Where the use is merely making the work available for others for personal use (e.g., reproductions for individual readers), no moral rights interest will overcome those purposes. Again, the purpose is to prevent harm to the author, not to restrict access to the work. Therefore, uses that are designed only for access or preservation, and carry no possible interpretation of an author's stamp of approval on the use, will not be hindered by moral rights.

${ }^{477}$ H.L.A. Hart, Are There Any Natural Rights?, 64 PHIL. ReV. 175 (1955). 


\section{Michelle M. Wu, Chapter from Copyright, Libraries, and the Public Interest}

However, where a use is made to advance a person, position, or product, or where a publicly distributed derivative work results, the author's interest in making clear her relationship to the effort is substantial. Why are these distinguished from other uses? A use to advance a person, position, or product is necessarily a position statement. The work is not being offered as mere information, but to support a value statement, usually along the lines of the goodness or rightness of the item or person.

Derivative works that are publicly distributed are also protected, as they have the potential of impacting the author's reputation, though in a different manner. In most instances, this will apply primarily to the shorter copyright term and free uses, as commercial uses would still need to be negotiated through the usual mechanisms and an author could exercise her rights through negotiation. A few examples of how derivative works could operate to injure an author's reputation: (1) if a free but poorly translated version of a work is widely distributed, it could damage the author's reputation by making it appear that the poor translation was authorized by her; (2) if a movie is bowdlerized, it may no longer contain the pieces that the author feels is necessary to convey her intended message; and (3) if a drawing of a childhood character is vulgarly modified, it could reduce interest in the character by its intended audience.

In these limited circumstances where moral rights will apply, the author would have three rights:

(1) To be notified of the intended use of the work;

(2) To require or ban the use of her name in relation to the work for the use proposed; and

(3) To preface the use with a statement of approval or disapproval, the statement of which must be displayed/played before every such use.

The first right is simply a notification right so that the author knows how her name is being used or how her work has been changed. Where the work is a joint work, all authors must be notified. The right carries a concomitant responsibility, though, and would be conditioned on the author's registering her contact information in a free national registry. Notification to the address registered would be deemed sufficient to meet the notice requirement, and any creator who fails to keep their contact information up to date may not claim to have had this right infringed if notice goes to the contact on record. The registry would provide an option for the author to explicitly grant blanket determinations on rights two and three. For instance, an author could state that any use of the work in political campaigns must be accompanied by a specific statement (e.g., "The artist disapproves of the use of the following song for any political purposes, and the use of the song is not an endorsement of the candidate by the artist.").

The second right is similar to the current rights of attribution and integrity, ${ }^{478}$ allowing the author to distance herself from uses, including derivative works, that she feels are contrary to the purpose of her work. This right goes further than the current statute in that (a) it is not limited to works of visual art, and (b) it does not limit the removal of her name only to situations where there is a "distortion, mutilation, or other modification of the work which would be prejudicial to his or her

${ }^{478} 17$ U.S.C. $\S 106 \mathrm{~A}$ (a) (2012). 


\section{Michelle M. Wu, Chapter from Copyright, Libraries, and the Public Interest}

honor or reputation. ${ }^{479}$ It is narrower, though, in that it does not give the author the right to stop modification, destruction, or distortion of the work/copy, as such is contrary to the principles of the right to alienate property. Once a person has legitimately acquired a manifestation of a work, he may destroy, modify or distort it, with the caveat that if he creates a derivative work for further redistribution, the moral rights clause would attach to the derivative work.

The last right merely offers the author a reasonable path for disassociation from views offensive to herself without suppressing access. She is under no obligation to issue a statement, but if she elects to use the right, any message would be limited in length (e.g., one sentence, no more than 30 words) to avoid the message being longer than the work itself. The unwieldiness in design of the third right is deliberate, intended to advantage the creator. After all, would a political campaign chose to use a song by an artist if every use of that song was preceded by a statement of how vile the artist feels the use or the user is? Such a statement would not only disrupt the flow of any event, advertisement, or speech, but could also reduce support for the user from an audience moved by the prefatory statement.

To create predictability for the potential user, an exercise of the second and third rights must be made within a set number of days (e.g., 30 days) of the notice of use. Failure to respond within that time, where there is no explicit blanket determination in the registry, will be deemed as approval to use the work with the author's name attached as the author, and without any prefatory statement. Where there is an applicable blanket statement in the registry, the artist's failure to respond does not relieve that user of the obligation to comply with the artist's exercise of her rights as stated in the registry.

Except in the case of willful infringement, the only remedy available for infringement of moral rights would be a non-financial, equitable one. For example, if a political campaign used someone's song without notice, the cure might come in the form of a mandated campaign message to its supporters noting the song's author disapproval of the use. The remedy in the case of moral rights is limited so as not to unduly depress the type of free, creative activities already thriving on platforms like YouTube.

\section{Works for Hire}

Some of the more troublesome aspects of copyright surface when examining works-for-hire. There are the author's interests in their livelihoods, where it is important not only to have an income stream but also to have their name associated with a work that they have created. The former contributes to basic living expenses, and the latter contributes to the building of a marketable portfolio. There is also an employer's interest in being able to recoup their investment in an employee and to fully exploit a work that they commissioned without the encumbrance of requiring approval from contributing artists. And there is the public interest in having certainty about who owns copyright in a work and therefore has the authority to exercise its exclusive rights.

These interests, particularly those of the employer and employee, are at direct odds with each other and cannot be evenly balanced. Public dispute over those interests have occasionally played out

47917 U.S.C. $§ 106 \mathrm{~A}(\mathrm{a})(2)(2012)$. 


\section{Michelle M. Wu, Chapter from Copyright, Libraries, and the Public Interest}

in the press, such as those between Jack Kirby and Marvel. ${ }^{480}$ The following proposal acknowledges the imbalance but chooses to continue the advantage of the employer over the employee, just as the current code does, ${ }^{481}$ with the purpose of promoting employment of artists by the entertainment industry. But, under certain circumstances, it provides both credit and minimal royalty rights to the creator to better represent the author's interests. The outline of the new work-for-hire doctrine is outlined below:

(1) Copyright is held by the employer, though it must be clearly noted as a work-for-hire. Exclusive rights can only be exercised by the employer;

(2) Any creator of the work has the right to have their name listed on every publication of the work as a creator;

(3) At least $5 \%$ of net income generated from the exploitation of the work must be distributed to the creator(s) that developed $25 \%$ or more of the work.

The first principle provides clarity to the public and potential investors on where copyright resides and who can negotiate the rights. It also provides an unambiguous statement that the creative effort behind the work was actually generated by someone other than the copyright owner.

The second speaks to the author's interest in being associated and credited for the work, even where she has no other rights, and the obligation to display the creator(s) names will attach regardless of how many times the copyright is conveyed to new owners.

The last requirement establishes a minimum of 5\% net income to be split across all creators who meet the $25 \%$ bar for contribution to a given work. Should the work be subsequently transferred, the obligation to pay the $5 \%$ transfers to the new owners as well. This provision ensures that creators will benefit, even if only slightly, when a work is unexpectedly popular and produces a windfall for the copyright owner. Admittedly, in application, there may be problems in assessment of more complex works, as there may not be a single "work" when it comes to characters built over many issues of a serial publications like comic books, where even the author and illustrator might change during the course of the character's run. Any good faith effort to make such a calculation, though, should be sufficient to protect the employer.

There would be one notable exception to the payment provision, and that is where the employer provides the specifications and instructions for design such that the author cannot be considered to be an independent actor. For example, where an employer hires a coder to build a program with specific instructions on purpose and functionality, and the coder, while perhaps free to use any programming language, is so closely tied to the specifications that her work would be considered an outgrowth of the employer's.

The 5\% for all other work-for-hire authors is not determined by any economic analysis but is more of a principled statement that the authors of a work deserve some of its profits just as the industry deserves to be credited for the investments that it has made. The provision is unlikely to

\footnotetext{
${ }^{480}$ Dominic Patten, Marvel \& Jack Kirby Heirs Settle Legal Battle Ahead Of Supreme Court Showdown, DEADLINE (September 26, 2014), https://deadline.com/2014/09/jack-kirby-marvel-settlement-lawsuit-supreme-court-hearing841711/

${ }^{481} 17$ U.S.C. $\S 201$ (b) (2012).
} 


\section{Michelle M. Wu, Chapter from Copyright, Libraries, and the Public Interest}

generate an enormous amount of money for any creator, but in the case where a work is hugely popular, it ensures that there are more beneficiaries than just the corporate copyright owner. The major creators of a work, or its derivatives, share in the success.

The $25 \%$ designation is similarly arbitrary and could as easily be any other number. The intent is to avoid an accounting burden where 100 or more people could arguably claim some hand in creating the work. By limiting this financial benefit only to creators who meet a minimum bar, there is no impediment to greater contributions but the burden on the employer is circumscribed. The unintended consequence of this right could be gaming by employers, by hiring 5 or more people to do the work of one, but for two reasons, this seems highly unlikely.

First, the cost of hiring five people instead of one for an endeavor whose potential success is not known at the outset is, in and of itself, a deterrent. Second, given the nature of creative work, it is hard to imagine that all five would be equal contributors and would therefore be equally cut out from the economic benefits.

Practically speaking, of course, there will always be works for which no artist has contributed $25 \%$ or more to the work. Movies based on preexisting works are an example, where the artists with notable contributions would include authors of the original work, the author of the screenplay, the director, the composer for the movie score, etc. Unfortunately, this is also where the shared economic benefit would be greatest, but as there is no way to measure contributions so intertwined with each other as to make percentages impossible to calculate, it is also where the third principle falls by the wayside.

These complicated scenarios should still result in some payment to artists, though not directly. In the example of the blockbuster movie above, the authors of the original work, if each contributed more than $25 \%$ to that work, would be entitled to $5 \%$ of any licensing fees paid for the use of that original work.

Criticisms of this approach are likely. The 5\% net base is minimal, and undoubtedly authors will see it as unfair that the monetary rewards of a work that they created largely fall elsewhere. On the flip side, employers may believe that the work would not have been created but for the employer's offer of a job. Later transferees may also see the approach as inequitable as they may view the commercial success of any derivative work as due to their envisioning, marking, and investment in actors. Each of these statements are true to varying degrees, with each person participating in the success of a work bearing different costs and gaining different benefits. For the reasons above, though, I believe that the proposal addresses identified inequities better than the existing code.

\section{Subject Matter of Copyright}

Three changes would be suggested for the subject matter of copyright. The first two would involve moving architectural and computer programs outside of the structure above, largely because they are different from other types of copyright. Both are highly functional and are intended to be highly functional even where design elements are involved. The design elements themselves could still be protected under copyright, as visual arts, and receive the same protection as above, but the functional pieces should not be viewed in the same light. 


\section{Michelle M. Wu, Chapter from Copyright, Libraries, and the Public Interest}

Despite separating these two works from other types, there remain sufficient interests in creators' rights to justify some protection of these works. In both cases, a single-shorter term --- 10 years --- for both free and commercial uses seems equitable, allowing each adequate time to sell their product. Given how quickly code and technology changes, the 10-year term should not deter a creator from investing time in creating programs. They should have ample time before the copyright term expires to sell their work.

In the case of architecture, buildings are visible and on file with necessary municipal offices once built, so longer protection similarly does not make sense. Since the 10 -year term does not run until publication, copyright would not expire until 10 years after the plan to build had been filed, and that amount of time should be adequate to build must structures. While there are buildings that have taken longer to build (e.g., Taj Mahal), current building practices make it likely that such future endeavors would be undertaken in phases with different architectural drawings (and therefore different copyright expiration dates) for each phase.

The last change in subject matter is to explicitly recognize characters as copyrightable and to define the elements necessary to obtain such protection. As characters are also fundamentally different from other types of copyright, constantly evolving as new details to the character are added through new stories, the terms of protection - 20 years for free use, 100 for commercial use - would run from the moment that the character is sufficiently formed to be recognizable as unique.

\section{Fair Use}

Fair use has stood well the test of time, changing technologies, and innovative uses. Despite the criticisms of fair use - primarily how impossible it is to predict the outcome of a fair use case - the danger in meddling with the language is that it risks more than it gains. The test is sufficiently adaptable only because it is broad and unlimited in the factors that can be considered. The language would be kept as is.

\section{Exhaustion}

Exhaustion principles would apply to all types of works and all formats. Any license that, through its terms, is essentially a transfer - as shaped by Carver's Perpetual Possession test (i.e. the seller intends for the buyer to have continued, perpetual access at the time of the transaction) ${ }^{482}$-- would be deemed a sale with the usual alienation rights attaching to the licensed work. This interpretation is not without precedent, as courts have noted that "[i]t is well-settled that in determining whether a transaction is a sale, a lease, or a license, courts look to the economic realities of the exchange." 483

\footnotetext{
${ }^{482}$ Brian W. Carver, Why License Agreements Do Not Control Copy Ownership: First Sales and Essential Copies, 25 BERKELEY TECH. L.J. 1887, 1954 (2010).

${ }^{483}$ SoftMan Prod. Co., LLC v. Adobe Sys., Inc., 171 F. Supp. 2d 1075, 1084 (C.D. Cal. 2001) (citing Microsoft Corp. v. DAK Indus., 66 F.3d 1091 (9th Cir. 1995)); U.S. v. Wise, 550 F.2d 1180 (9th Cir. 1977); Brian W. Carver, Why License Agreements Do Not Control Copy Ownership: First Sales and Essential Copies, 25 BERKELEY TECH. L.J. 1887, 1954 (2010) (advocating for using a Perpetual Possession test, in that if the licensee is intended to have perpetual possession of content that is licensed, it should be treated as a sale).
} 


\section{Michelle M. Wu, Chapter from Copyright, Libraries, and the Public Interest}

Mass producers of works would still be able to provide blanket access licenses at low cost but would be required to provide a purchase option for each work. If the purchase price is deemed unreasonable (e.g., \$100 for a song) in light of average market costs, users would have a new cause of action, to claim misuse of the copyright, with a potential remedy being that the actor loses their rights, reverting control of copyright back to the creator.

Technology has now advanced to the point that first sale can safely be applied to digital items while limiting risk. Whether through blockchain ${ }^{484}$ or digital rights management, ${ }^{485}$ digital items can be locked and controlled or set to disappear upon transfer of rights. While some may argue that any technological tool carries risk, as it can be hacked, both technologies are broadly in use now, including by publishers, without great harm. ${ }^{486}$ Further, section 1201 provides a cause of action against anyone who does circumvent technology to obtain to copyrighted content. ${ }^{487}$

By allowing all legitimately-acquired copies to be alienated, this proposal aims to restore the balance of copyright interests that existed with print materials. The owner of the copy has full use of the copy, including the rights to reconvey, while the copyright owner has full rights to control the first conveyance but not subsequent ones.

\section{Circumvention}

Circumvention is considered a copyright-adjacent issue but deserves some mention here.

Circumvention is essentially the hacking of technology that controls a copyrighted work (e.g., the digital rights management applied to an e-book to prevent its copying or sharing). Currently, both civil and criminal liability can attach to circumvention, and the broad exceptions applying to copyright do not apply to acts of circumvention. The change suggested here is to apply all exceptions to circumvention in a manner similar to how they operate with copyright.

How this might work: a user who has purchased a technologically-locked-down e-book in a particular format (e.g., Kindle) but who no longer has access to the technology to read it, may break the technology to access/read the work on a different application. Should the user hack the technology to make multiple copies for resale or retain copies made through circumvention after reconveyance of the underlying legitimately-acquired copy, though, then she could find herself facing both copyright infringement charges and civil or criminal liability for circumvention.

The rationale for exceptions to circumvention are largely the same as those for narrowing the exclusive rights of copyright. A user should have the right to use a work that he has legitimately acquired, even if it means accessing the work through unconventional means. Unless the copy is

\footnotetext{
${ }^{484}$ Two companies are already using blockchain for distribution: Scenarex, https://www.scenarex.ca/en/bookchain/, and Publica, https://www.scenarex.ca/en/bookchain/.

${ }^{485}$ Common DRM platforms like Adobe Digital Editions (https://www.adobe.com/solutions/ebook/digitaleditions.html) and Overdrive (https://www.overdrive.com/) are already used by publishers and libraries for lending, but similar technologies could be tied to sales, with the expiration of access on the seller's device set when the new owner acquires it.

${ }^{486}$ Admittedly, whether there is harm, as well as how much harm, is hotly debated, as noted in earlier chapters. The reason this books takes the position that there is little harm is because, even where piracy is found, there is no data that supports the idea that the people who consumed the pirated version would have paid for copy. And the data that has been provided by industries on piracy have already been discredited many times over.

487 17 U.S.C. $\S 1201$.
} 


\section{Michelle M. Wu, Chapter from Copyright, Libraries, and the Public Interest}

distributed publicly or used by more than one person at a time, the copyright owner has no legitimate interest in controlling either circumvention or use.

\section{Damages}

As discussed in earlier chapters, statutory damage provisions as currently written deter innovation simply because of the multiplication factor involved with every perceived infringement. Industries can and have pursued statutory damages against individuals for thousands if not millions, ${ }^{488}$ even in cases where was no actual proof of infringement, ${ }^{489}$ and the sheer amount possible to obtain through statutory damages encourages overuse and intimidation tactics.

For that reason, no statutory damages should be permitted, with any compensation tied directly to actual damages and costs plus punitive damages where the infringer has knowingly and willfully violated the law, ${ }^{490}$ with no reasonable belief that his actions fell under one of the exceptions (e.g., fair use) in the code. Punitive damages could also be awarded for repeat offenders, deceptive behavior (e.g. claiming owned a work when did not), or other gross malfeasance.

\section{Conclusion}

In suggesting an alternative copyright framework, I am not intimating that this is the only, or even necessarily the best, configuration. But it is one that pushes against commonly accepted principles, such as a singular, indivisible copyright term and that overall does a better job at serving the public's and the average author's interests than our current set of laws. The public deserves to be served in a more meaningful manner than it is now, and given the growing wealth gap across the nation, ${ }^{491}$ our attention should focus not only on how to narrow the gap but also how to prevent that gap from increasing divides elsewhere, such as in information.

\footnotetext{
${ }^{488}$ Record Industry Sues Hundreds of Internet Music Swappers, N.Y. TIMES (Sept. 8, 2003), https:/www.nytimes.com/2003/09/08/technology/record-industry-sues-hundreds-of-internet-music-swappers.html. 489 Joe Dangelo, RIAA Drops Piracy Suit Against 66-Year-Old Grandmother, MTV (Sept. 9, 2003), http:/www.mtv.com/news/1479303/riaa-drops-piracy-suit-against-66-year-old-grandmother/.

${ }^{490}$ An example of what type of action might constitute "knowingly and willfully," see Tenenbaum's conduct as described in Sony BMG Music Entm't v. Tenenbaum, 660 F.3d 487, 495 (1st Cir. 2011).

491 Thomas Piketty, Capital in the Twenty-First Century (Arthur Goldhammer trans., 2013); Jaison R. Abel \& Richard Deitz, Why Are Some Places So Much More Unequal Than Others?, 25 ECON. POL'Y REV. 58 (2019), https://www.newyorkfed.org/medialibrary/media/research/epr/2019/epr_2019_wage-inequality_abel-deitz.pdf.
} 